\title{
MicroRNA-24 Modulates Aflatoxin B1-Related Hepatocellular Carcinoma Prognosis and Tumorigenesis
}

\author{
Yi-Xiao Liu, ${ }^{1}$ Xi-Dai Long, ${ }^{1,2}$ Zhi-Feng Xi, ${ }^{1}$ Yun Ma, ${ }^{3}$ Xiao-Ying Huang, ${ }^{2}$ \\ Jin-Guang Yao, ${ }^{2}$ Chao Wang, ${ }^{4}$ Tian-Yu Xing, ${ }^{1}$ and Qiang Xia ${ }^{1}$ \\ ${ }^{1}$ Department of Liver Surgery, Ren Ji Hospital, School of Medicine, Shanghai Jiao Tong University, Dongfang Road, \\ No. 1630, Shanghai 200127, China \\ ${ }^{2}$ Department of Pathology, Youjiang Medical College for Nationalities, Baise 533000, China \\ ${ }^{3}$ Department of Pathology, The Affiliated Tumor Hospital, Guangxi Medical University, Nanning 530021, China \\ ${ }^{4}$ Department of Medicine, The Affiliated Hospital of Youjiang Medical College for Nationalities, Baise 533000, China
}

Correspondence should be addressed to Xi-Dai Long; sjtulongxd@263.net

Received 23 January 2014; Revised 13 March 2014; Accepted 16 March 2014; Published 8 April 2014

Academic Editor: Chunping Jiang

Copyright (C) 2014 Yi-Xiao Liu et al. This is an open access article distributed under the Creative Commons Attribution License, which permits unrestricted use, distribution, and reproduction in any medium, provided the original work is properly cited.

\begin{abstract}
MicroRNA-24 (miR-24) may be involved in neoplastic process; however, the role of this microRNA in the hepatocellular carcinoma (HCC) related to aflatoxin B1 (AFB1) has not been well elaborated. Here, we tested miR-24 expression in 207 pathology-diagnosed HCC cases from high AFB1 exposure areas and HCC cells. We found that miR-24 was upregulated in HCC tumor tissues relative to adjacent noncancerous tissue samples, and that the high expression of miR-24 was significantly correlated with larger tumor size, higher microvessel density, and tumor dedifferentiation. Additionally, this microRNA overexpression modified the recurrence-free survival (relative hazard ratio [HR], 4.75; 95\% confidence interval $[\mathrm{CI}], 2.66-8.47)$ and overall survival $(\mathrm{HR}=3.58,95 \% \mathrm{CI}=$ 2.34-5.46) of HCC patients. Furthermore, we observed some evidence of joint effects between miR-24 and AFB1 exposure on HCC prognosis. Functionally, miR-24 overexpression progressed tumor cells proliferation, inhibited cell apoptosis, and developed the formation of AFB1-DNA adducts. These results indicate for the first time that miR-24 may modify AFB1-related HCC prognosis and tumorigenesis.
\end{abstract}

\section{Introduction}

Hepatocellular carcinoma (HCC) remains a life-threating malignancy, accounting for more than $90 \%$ of primary liver cancer. This tumor is the sixth most commonly occurring cancer worldwide, with an estimated 600,000 new cases per year. More than $80 \%$ of all HCC cases occurred in developing countries, and approximately $55 \%$ of all cases occur in China (especially in the southeast areas such as Guangxi) [1, 2]. Because of the very poor prognosis resulting from metastasis and reoccurrence, HCC is the third leading cause of cancerrelated deaths in the world [3]. Therefore, improvement in the therapy of recurrent or metastatic HCC now depends on improving our understanding of the complex molecular mechanisms governing the progression and aggressiveness of the disease, and looking for valuable prognostic markers and therapeutic targets.

MicroRNAs are small, endogenous, and noncoding RNAs that regulate the translation of protein-coding genes by repressing translation of protein-coding $\mathrm{mRNA}$ or enhancing mRNA degradation $[4,5]$. Deregulation of microRNAs has been reported to modulate normal cell growth and differentiation, potentially leading to a variety of disorders, including cancer $[6,7]$. To date, there are more than 2000 annotated human mature microRNAs in the official registry (the MicroRNA Registry) [8]. Among these microRNAs, miR-24 has been shown to regulate the carcinogenesis of a variety of cancers including HCC [9-13]. However, association between this microRNA and aflatoxin B1 (AFB1)related HCC prognosis has not yet been elucidated. Here, 
we evaluated whether miR-24 expression modified HCC tumorigenesis and prognosis.

\section{Materials and Methods}

2.1. HCC Patients. During the period from January 2004 to December 2008, all incident cases with the I-II tumor-nodesmetastasis (TNM) stage HCC were recruited at the affiliated hospitals Guangxi Medical University and Youjiang Medical College for Nationalities. All patients were the residents of Guangxi Zhuang Autonomous Region, a high AFB1 exposure area. A total of 207 HCC cases, including 138 patients previously studied [14-16], were included for the present study. All cases were histopathologically confirmed and previously untreated with chemotherapy or radiotherapy. In this study, the response rate for the cases has been about $95 \%$. The study protocol was been carried out in accordance with "Ethical Principles for Medical Research Involving Human Subjects" (World Medical Association Declaration Of Helsinki, 2004) and approved by institutional review boards from Guangxi Cancer Institute and the Medical Research Council from the corresponding hospitals.

2.2. Samples and Data Collection. After informed consent was obtained, surgically removed tumor samples and adjacent noncancerous tissue samples (at least $5 \mathrm{~cm}$ from the margin of the tumor) of all cases were collected for analyzing miR-24 expression levels and AFB1-DNA adduct levels. Demographic information (including sex, age, ethnicity, hepatitis $B$ virus $[\mathrm{HBV}]$, and hepatitis $\mathrm{C}$ virus $[\mathrm{HCV}]$ infection) and clinical pathological data (including cirrhosis, tumor size, tumor differentiation, and tumor stage) were collected in the hospitals using a standard interviewer-administered questionnaire and/or medical records by a Youjiang Cancer Institution staff member. In this study, those with hepatitis B surface antigen (HBsAg) positive and anti-HCV positive in their peripheral serum were defined as groups infected with HBV and HCV. Liver cirrhosis was diagnosed by pathological examination, and stages of tumor were confirmed according to the tumor nodes metastasis (TNM) staging system. For tumor grading, Edmondson and Steiner grading system was used to evaluate the differentiation status of HCC in this study [17].

For survival analysis, we followed all HCC cases and more detailed follow-up information was described in our previous studies [14-16, 18]. Briefly, all patients underwent serial monitoring every 2 months for the first 2 years and semiannually thereafter for detection of any recurrence. In the present study, the last follow-up day was set on August 31,2013 , and survival status was confirmed by means of clinic records and patient or family contact. The duration of the duration of overall survival (OS) was defined as from the date of curative treatment to the date of death or last known date alive; whereas the recurrence-free survival (RFS) was defined as from the date of curative treatment to the date of tumor recurrence or last known date alive [14, 15].

2.3. DNA and RNA Detraction. Genomic DNA was extracted from HCC tumor tissues and SMMC-7721 cells in a $1.5 \mathrm{~mL}$ microcentrifuge tube for deparaffinization and proteinase $\mathrm{K}$ digestion, as described by standard procedures (Protocol \#BS474, Bio Basic, Inc., Ontario, Canada). For RNA detraction, total RNA was isolated from tissue or cell cultures, using PureLink RNA minikit (cat number 12183018A, Ambion, USA) according to manufacturer's instructions.

2.4. AFB1 Exposure Analysis. In this study, AFB1 exposure levels were evaluated using the levels of AFB1-DNA adducts in tumor tissues. The amount of AFB1-DNA adducts in cancerous tissues samples was evaluated by means of competitive enzyme-linked immunosorbent assay (ELISA) [19]. To convert any N-7 adduct to AFB1-FAPy adducts, DNA was treated with $15 \mathrm{mM} \mathrm{Na}_{2} \mathrm{CO}_{3}$ and $30 \mathrm{mM} \mathrm{NaHCO}$ ( $\mathrm{pH} 9.6$ ) for 2 hours, precipitated with 2.5 volumes of $95 \%$ ethanol, and then redissolved in $10 \mathrm{mM}$ Tris- $\mathrm{HCl}(\mathrm{pH}$ 7.0). The DNA samples were reprecipitated, dissolved in $1 \times$ PBS, and denatured by boiling for $5 \mathrm{~min}$. After that, AFB1-FAPy adducts were quantitated by ELISA using monoclonal antibody $6 \mathrm{~A} 10$ (Novus Biologicals LLC, catalog number NB600-443). For analysis, AFB1-DNA adduct levels were divided into two groups: low level $(\leq 2.87 \mu \mathrm{mol} / \mathrm{mol} \mathrm{DNA})$ and high level $(>2.87 \mu \mathrm{mol} / \mathrm{mol} \mathrm{DNA})$, according to the average value of AFB1-DNA adduct levels among cases.

2.5. The Microvessel Density (MVD) Evaluation. In the present study, the angiogenesis of cancerous tissues was assessed using the IHC staining of CD31 (cat number 2011101101, Gene Tech (Shanghai) Company Limited, Shanghai, China). At $\times 200$ magnification, vessel counts were made of all distinct brown staining endothelial cells in the cancerous regions over five fields in each slide. The microvessel density (MVD) was defined as the average value of the three readings. To analysis the relationship between miR24 expression and angiogenesis in the cancerous tissues, the angiogenesis status was divided into two groups: low $(\leq 50 / \times 200$ magnifications $)$ and high $(>50 / \times 200$ magnifications), according to the mean MVD of cancerous-tissues vessels.

2.6. MiR-24 Expression Assay. The level of miR-24 expression was analyzed using our previously published TaqMan quantitative reverse transcription-PCR technique [16]. In brief, RNA was reversed transcribed into cDNA using high capacity cDNA reverse transcription kit (cat number 4368814, Invitrogen) and TaqMan microRNA reverse transcription kit (cat number 4366596, Applied Biosystems [ABI], Carlsbad, CA), according to the manufacturer's instructions. In this study, U6 expression was used as an internal control. Real-time quantitative PCR with TaqMan probes (cat number 4427975, $\mathrm{ABI}$ ) was performed in total volume of $5 \mu \mathrm{L}$ containing 1 $\times$ TaqMAN Universal Master Mix II (cat number 4440041, $\mathrm{ABI}), 1 \times$ TaqMan microRNA probe and primer Mix, and about $15 \mathrm{ng}$ of cDNA using the running conditions: $95^{\circ} \mathrm{C}$ for $30 \mathrm{~s}$, and 50 cycles of $95^{\circ} \mathrm{C}$ for $15 \mathrm{~s}$ and $60^{\circ} \mathrm{C}$ for $1 \mathrm{~min}$. All reactions were conducted in triplicate and controls were performed with no template or no reverse transcription for each gene. The cycle number at which the reaction crossed 
an arbitrarily placed threshold (CT) was determined for each gene. For the relative expression of miR-24 in cancer cells, miR-24 expression was normalized to endogenous controls U6 by the comparative CT method $\left(2^{-\Delta \Delta \mathrm{Ct}}\right.$ method). For tissue samples, the relative amount of miR-24 to U6 was calculated as $2^{-\Delta \mathrm{Ct}}$ method, where $\Delta \mathrm{Ct}=\left(\mathrm{Ct}_{\mathrm{miR}-24}-\mathrm{Ct}_{\mathrm{U6}}\right)$. To analyse, miR-24 expression levels were divided into two groups: low expression group, $2^{-\Delta \mathrm{Ct}} \leq 2.95$; and high expression group, $2^{-\Delta \mathrm{Ct}}>2.95$, according to the average value among HCC cases.

2.7. Cell Lines and Culture. The QSG7701 cells (a kind of peritumoral liver cells) and HCC cells (including SMMC7721, HepG2, and HCCLM3) were obtained from the Cell Bank of Shanghai Institute of Cell Biology of the Chinese Academy of Sciences and Shanghai Xinran Ltd. (Shanghai, China). Cells were cultured in DMEM medium (HyClone, Thermo Fisher Scientific (China) CO., Ltd., Shanghai, China) containing high glucose and L-glutamine supplemented with $10 \%$ fetal bovine serum at $37^{\circ} \mathrm{C}$ in an atmosphere of $5 \% \mathrm{CO}_{2} / 100 \%$ humidity. All experimental analyses were done with cells in logarithmic growth. Cells were determined to be free of mycoplasma.

2.8. AFB1 Toxicity Analysis. Cells were transfected with an miR-24 mimic, its inhibitor, its mock, or null control (GenePharma, China) using Lipofectamine 2000 (cat number 11668-027, Invitrogen Grand Island, NY, USA) according to the manufacturer's instructions. According to the types of mimics transfected, cell lines were divided into four groups: control group (control, by null mimics), mock group (mock, by mock mimics); miR-24 group (miR-24, by mature miR24 mimics), and inhibitor group (inhibitor, by inhibitor of mature miR-24). In this study, transfection efficacy was evaluated as the ratio of transfected cells detected by the LV200 system to total cells obtained from three different regions at random and was about $40 \%$. AFB1 toxicity value was evaluated as our previously published methods [15]. Briefly, 48 hours after transfections, cells were treated with AFB1 (Sigma) at final concentrations of $24 \mathrm{nM}$ for 1 day, and then the DNA was extracted for AFB1-DNA adduct analysis.

\subsection{Cell Transfection and Cell Proliferation and Apoptosis} Assay. The cell proliferation assay was measured using a cell counting kit (CCK-8) assay (cat number CK04, Dojindo Corp., Japan) according to the manufacturer's instructions. A total of 2500 cells were seeded each well in a 96-well plate. Ten microliters of CCK- 8 solution was added into $100 \mu \mathrm{L}$ of culture media and incubated for 2 hours at $37^{\circ} \mathrm{C}$. Finally, the absorbance of optical density (at $450 \mathrm{~nm}$ ) was measured using UV spectrophotometer at 72 hours after transfection. The assay was performed three times in eight replicates. To analyse, relative proliferation value (RPV) of different groups to control group was calculated as $\mathrm{OD} 250_{\mathrm{XG}} / \mathrm{OD} 250_{\mathrm{Ref}}$, where OD250 ${ }_{\mathrm{XG}}$ represented OD250 value for cell proliferation analysis for different groups, and OD250 ${ }_{\text {Ref }}$ represented OD250 value for cell proliferation analysis for control group.
In this study, cell apoptosis was analyzed by the flow cytometry technique using Annexin V, FITC apoptosis detection kit (cat number AD10-10, Dojindo Corp., Japan). Cells were seeded 6-wells and the transfections were performed when cells reached $70 \%$ confluent. 48 hours after transfection, cells were harvested, washed, and resuspended for cell apoptosis analysis. To analyse, relative apoptosis value (RAV) of different groups to control group was calculated using the following formula:

$$
\mathrm{RAV}=\frac{\mathrm{PPC}_{\mathrm{XG}}}{\mathrm{PPC}_{\mathrm{Ref}}},
$$

where $\mathrm{PPC}_{\mathrm{XG}}$ represented the percent of positive cells with apoptosis for different groups, and $\mathrm{PPC}_{\mathrm{Ref}}$ represented the percent of apoptosis positive cells for control group.

2.10. Statistical Analysis. MiR-24 expression among different tissues and cells was compared by independent two-sample $t$-test and Mann-Whitney $U$ test for two groups, or one-way ANOVA with Bonferroni corrections for three or more than three groups. Nonconditional logistic regression was used to evaluate odds ratios (ORs) and 95\% confidence intervals (CIs) for the effects of miR-24 expression on the pathological features of HCC (including AFB1-DNA adducts, tumor size, tumor differentiation, and MVD). Kaplan-Meier survival analysis (with the log-rank test) was used to evaluate the association between miR-24 expression and HCC prognosis. Hazard ratios (HRs) and 95\% CIs for miR-24 expression were calculated from multivariate Cox regression model. In this study, a $P$ value of less than 0.05 was considered statistically significant. All analyses were performed with the statistical package for social science (SPSS) version 18 (SPSS Institute, Chicago, IL, USA).

\section{Results}

3.1. The Characteristics of HCC Patients. Table 1 showed the demographic and clinic-pathological data of the cases. The present study comprised 207 HCC patients with 189 (91.3\%) males and $18(8.7 \%)$ females. The mean age was $46.9 \pm 11.5$ years. Among these patients, more than $80 \%$ of cases were infected by HBV, and most of them had liver cirrhosis. One hundred percent of patients featured HCC with I-II TNM stage and received the same curative resection treatment, according to Chinese Manage Criteria of HCC. During the follow-up period of these patients, 72 faced tumor recurrence with $61.3 \%$ of the 5 -year RFS rate, and 115 died with $47.5 \%$ of the five-year OS rate.

3.2. AFB1 Exposure Levels Related to Poor Prognosis of HCC Patients. In this study, we elucidated AFB1 exposure levels through testing AFB1-DNA adducts of DNA samples from cancerous tissue of the patients and found the mean of $2.87 \pm$ $1.60 \mu \mathrm{mol} / \mathrm{mol}$ DNA. To analyze the effects of AFB1 exposure on HCC prognosis, this variable was divided into two groups: low and high level. Results showed high AFB1 exposure levels were associated with decreasing 1-year, 3-year, and 5year survival rate (Figure 1 and Table 2). Multivariate Cox 
TABLE 1: Characteristics of the patients with HCC.

\begin{tabular}{|c|c|}
\hline \multicolumn{2}{|c|}{ Characteristics } \\
\hline Age, year & \\
\hline Mean \pm SE & $46.9 \pm 11.5$ \\
\hline Range & $15-75$ \\
\hline \multicolumn{2}{|l|}{ Sex } \\
\hline Man, $n(\%)$ & $189(91.3)$ \\
\hline Female, $n(\%)$ & $18(8.7)$ \\
\hline \multicolumn{2}{|l|}{ Ethnicity } \\
\hline Han, $n(\%)$ & $163(78.7)$ \\
\hline Minority, $n(\%)$ & $44(21.3)$ \\
\hline \multicolumn{2}{|l|}{ HBV infection } \\
\hline HBsAg $(-), n(\%)$ & 33 (15.9) \\
\hline HBsAg $(+), n(\%)$ & $174(84.1)$ \\
\hline \multicolumn{2}{|l|}{ HCV infection } \\
\hline anti-HCV (-), $n(\%)$ & $204(98.6)$ \\
\hline anti-HCV (+), $n(\%)$ & $3(1.4)$ \\
\hline \multicolumn{2}{|l|}{ Smoking status } \\
\hline No, $n(\%)$ & $165(79.7)$ \\
\hline Yes, $n(\%)$ & $42(20.3)$ \\
\hline \multicolumn{2}{|l|}{ Drinking status } \\
\hline No, $n(\%)$ & $167(80.7)$ \\
\hline Yes, $n(\%)$ & $40(19.3)$ \\
\hline \multicolumn{2}{|l|}{ Liver cirrhosis } \\
\hline No, $n(\%)$ & $41(19.8)$ \\
\hline Yes, $n(\%)$ & $166(80.2)$ \\
\hline \multicolumn{2}{|l|}{ TNM stage } \\
\hline I, $n(\%)$ & $13(6.3)$ \\
\hline II, $n(\%)$ & $194(93.7)$ \\
\hline \multicolumn{2}{|l|}{ Tumor size } \\
\hline$\leq 5 \mathrm{~cm}, n(\%)$ & $101(48.8)$ \\
\hline$>5 \mathrm{~cm}, n(\%)$ & $106(51.2)$ \\
\hline \multicolumn{2}{|l|}{ Tumor grade } \\
\hline I & $44(21.3)$ \\
\hline II & $106(51.2)$ \\
\hline III & $54(26.1)$ \\
\hline IV & $3(1.4)$ \\
\hline Total, $n(\%)$ & $207(100)$ \\
\hline
\end{tabular}

regression analysis (with stepwise forward selection based on likelihood ratio test) exhibited that this variable increased dying risk and tumor reoccurring risk of HCC, with an HR of 2.12 and $2.40(P<0.01$; Figure 1$)$, respectively.

3.3. MiR-24 Was Upregulated in HCC Samples and in HCC Cells. We performed the real-time PCR experiment to detect the expression of mature miR-24 RNA in HCC tumor tissues and adjacent noncancerous tissues. Through comparing $\mathrm{Ct}$ values in these two types of tissues, we evaluated the significance of different miR-24 expression and observed that miR-24 expression was significantly higher in tumour tissues (TT) than in nonmalignant adjacent liver tissues (NT), with a relative expression value of $2.95 \pm 1.88$ versus $1.73 \pm 0.92$
$(P<0.01$, Figure $2(\mathrm{a}))$. We also found similar results in the expression analysis of this microRNA in HCC cell lines and nontumor liver cell lines QSG7701 $\left(P=3.82 \times 10^{-4}\right.$, Figure 2(b)). Furthermore, higher expression of miR-24 was observed in the HCCLM3 (a kind of poor differentiated HCC cells with high infiltrating capacity) cells compared to in the HepG2 (a kind of good differentiated HCC cells with low infiltrating capacity).

3.4. MiR-24 Expression Was an Independent Factor of HCC Prognosis. To investigate the effects of miR-24 expression on outcome of HCC patients, we divided miR-24 expression in cancerous tissues into two groups: low expression group (relative level $\leq 2.95$ ) and high expression group (relative level > 2.95), according to the average relative expression levels. Kaplan-Meier survival analysis showed that patients with high miR-24 expression featured a significantly poorer prognosis than those with low miR-429 expression $(P=$ $2.00 \times 10^{-10}$ for RFS and $P=1.92 \times 10^{-12}$ for OS, resp., Figure 3). Multivariate Cox regression analysis (with stepwise forward selection based on likelihood ratio test) was next performed to determine whether miR-24 expression was an independent predictor of HCC cases. The results exhibited that high miR-24 expression increased the risk of tumor reoccurrence compared with low expression $(\mathrm{HR}=4.75,95 \%$ $\mathrm{CI}=2.66-8.47, P=1.38 \times 10^{-7}$, Figure $\left.3(\mathrm{a})\right)$. Risk role was also found in the OS analysis; the corresponding HR (95\% CI) was 3.58 (2.34-5.46), with a $P$ value of $3.51 \times 10^{-9}$ (Figure $3(\mathrm{~b})$ ). Taken together, these results suggested that this microRNA could be used as an independent prognostic marker for HCC.

3.5. Joint Effects of miR-24 Expression and AFB1 Exposure on HCC Prognosis. To investigate the joint effects between miR-24 expression and AFB1 exposure on HCC prognosis, we performed a stratified analysis based on AFB1 exposure levels (Figure 4). We found lower 5-year RFS and OS for high miR-24 expression among these cases with high level of AFB1-DNA adducts (Figures 4(b) and 4(d)) than among those without high level of AFB1-DNA adducts (Figures 4(a) and 4(c)), suggesting high miR-24 expression might interact with AFB1 exposure in the process of HCC carcinogenesis. Next, a joint analysis between miR-24 expression and AFB1 exposure was accomplished (Figure 5). In this analysis, we used as a reference the lowest risk group: those who had both low AFB1-DNA adducts level and low miR-24 expression (LALM). Results showed that increasing adducts amount decreased 5-year survival rate of HCC; moreover, this effect was more pronounced among the high miR-24 expression subjects (Figures 5(a) and 5(c)). Moreover, compared to those with LALM, these with high AFB1-DNA adducts level and high miR-24 expression (HAHM) featured increasing tumor reoccurring risk $(\mathrm{HR}=11.75,95 \% \mathrm{CI}=5.15-26.79$, Figure $5(\mathrm{~b}))$ and death risk $(\mathrm{HR}=8.13,95 \% \mathrm{CI}=4.46-14.84$, Figure 5(d)).

3.6. MiR-24 Expression Associated with the Clinic-Pathological Features of HCC Patients. To explore possible pathogenesis 


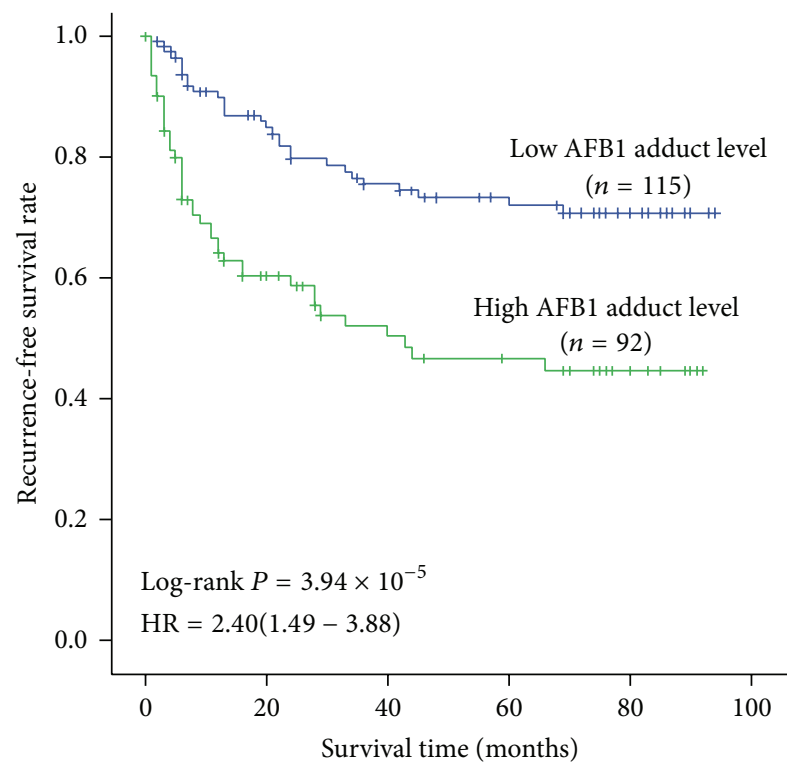

(a)

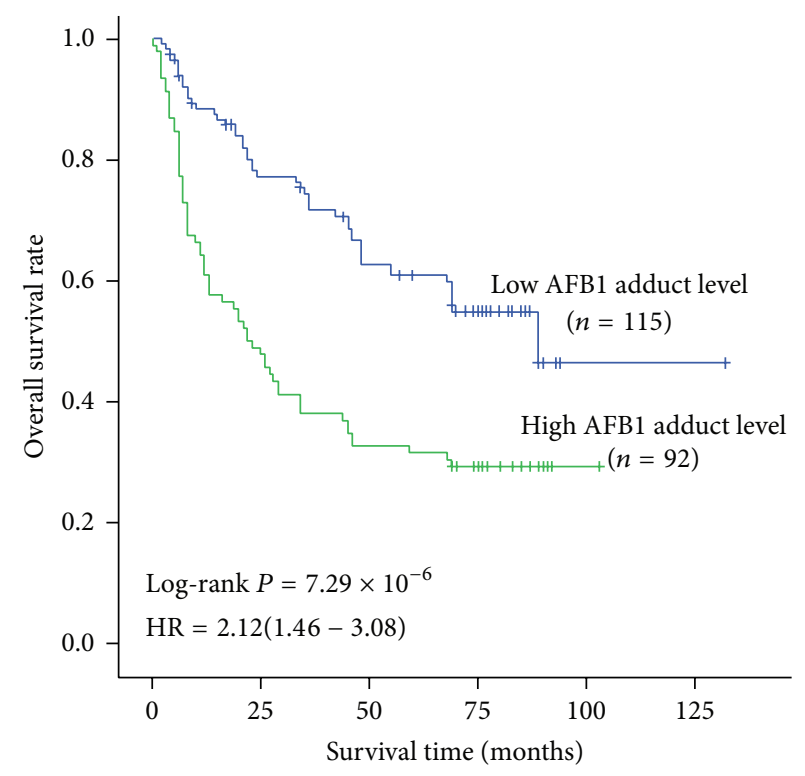

(b)

FIGURE 1: Association between survival and AFB1 exposure in 207 HCC cases receiving curative treatment. According to the average level of AFB1-DNA adducts in cancerous tissues, AFB1 exposure was divided into two groups: low exposure group (relative level $\leq 2.87 \mu \mathrm{mol} / \mathrm{mol}$ DNA) and high exposure group (relative level $>2.87 \mu \mathrm{mol} / \mathrm{mol}$ DNA). AFB1 exposure levels were associated with tumor reoccurrence-free survival (a) and overall survival (b) of HCC. Cumulative hazard function was plotted by Kaplan-Meier's methodology, and $P$ value was calculated with two-sided log-rank tests. Relative hazard ratio (HR) and corresponding 95\% CI of high AFB1 exposure (compared with low exposure) was calculated using multivariable cox regression model (including all significant variables).

TABLE 2: RFS rate and OS rate of HCC cases.

\begin{tabular}{|c|c|c|c|c|c|c|c|}
\hline & & \multicolumn{3}{|c|}{ RFS rate (\%) } & \multicolumn{3}{|c|}{ OS rate $(\%)$} \\
\hline & & 1 year & 3 years & 5 years & 1 year & 3 years & 5 years \\
\hline \multirow{3}{*}{ Figure 1} & AFB1-DNA adduct level & & & & & & \\
\hline & Low & 89.9 & 75.5 & 70.8 & 88.4 & 74.4 & 60.9 \\
\hline & High & 66.7 & 53.9 & 46.7 & 64.1 & 41.3 & 31.5 \\
\hline \multirow{3}{*}{ Figure 3} & miR-24 expression & & & & & & \\
\hline & Low & 97.8 & 88.1 & 82.9 & 94.5 & 82.3 & 72.0 \\
\hline & High & 65.2 & 44.4 & 41.2 & 61.1 & 37.7 & 27.3 \\
\hline \multirow{3}{*}{ Figures 4(a) and 4(c) } & miR-24 expression & & & & & & \\
\hline & Low & 100 & 91.1 & 87.3 & 96.6 & 89.7 & 84.3 \\
\hline & High & 86.8 & 55.7 & 52.6 & 79.2 & 56.5 & 33.5 \\
\hline \multirow{3}{*}{ Figures 4(b) and 4(d) } & miR-24 expression & & & & & & \\
\hline & Low & 93.8 & 81.9 & 73.2 & 90.6 & 68.8 & 50.0 \\
\hline & High & 50.7 & 33.9 & 30.5 & 48.3 & 25.0 & 20.0 \\
\hline
\end{tabular}

of miR-24 expression modifying the outcome of AFB1related $\mathrm{HCC}$, we analyzed the distribution difference of this microRNA expression among different clinic-pathological characteristics of cases. Results showed these HCC cases with high miR-24 expression, compared to those with low miR-24 expression, faced larger tumor size $(\mathrm{OR}=2.01)$, lower tumor differentiation $(\mathrm{OR}=2.10)$, and higher $\mathrm{MVD}(\mathrm{OR}=2.63$, Table 3). However, the expression of this microRNA did not affect other features (data not shown).
3.7. MiR-24 Expression Modified HCC Cell Proliferation. We evaluated the functional role of miR-24 in HCC cells by means of measuring cell proliferation in HCC cells which were transfected with miR-24 mimics and its inhibitor. Overexpression of miR-24 in HCC cells promoted proliferation while downregulation of miR-24 in HCC cells inhibited cell proliferation. On the other hand, compared with the mock group, the proliferation of tumor cells in the inhibitor groups was inhibited significantly $(P<0.05$, Figure 6(a)). 


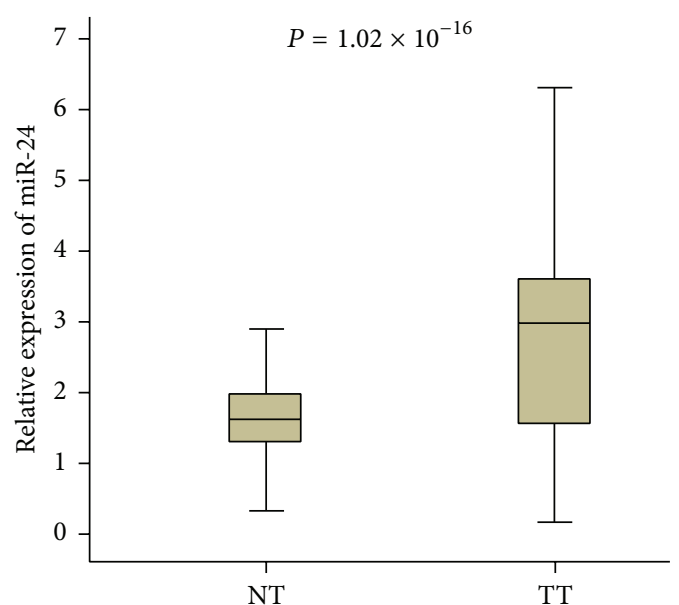

(a)

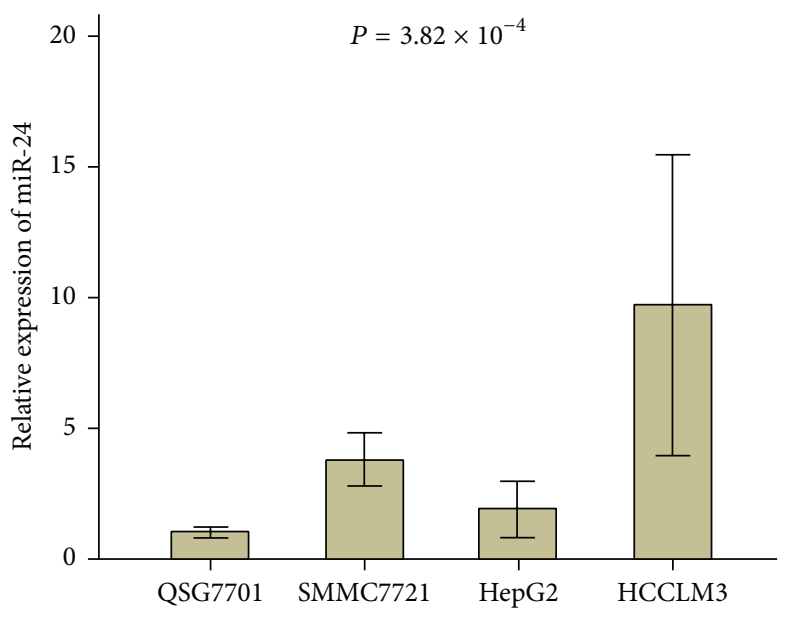

(b)

FIGURE 2: MiR-24 expression related with HCC tumorigenesis. (a) miR-24 expression was evaluated in the tumor tissues versus in the adjacent noncancerous tissues. The relative expression of miR-24 is shown as box plots, with horizontal lines representing the median, the bottom, and the top of the boxes representing the 25th and 75th percentiles, respectively, and vertical bars representing the range of data. We compared the difference among group using the Mann-Whitney $U$ test. (b) miR-24 expression was higher in cancer cell line SMMC-7721 than in noncancer cell line QSG-7701.

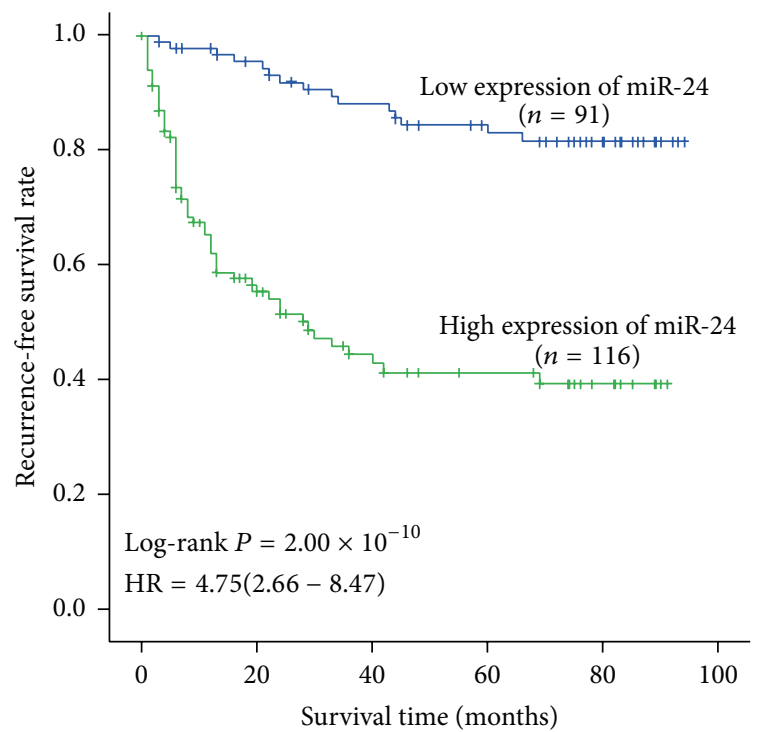

(a)

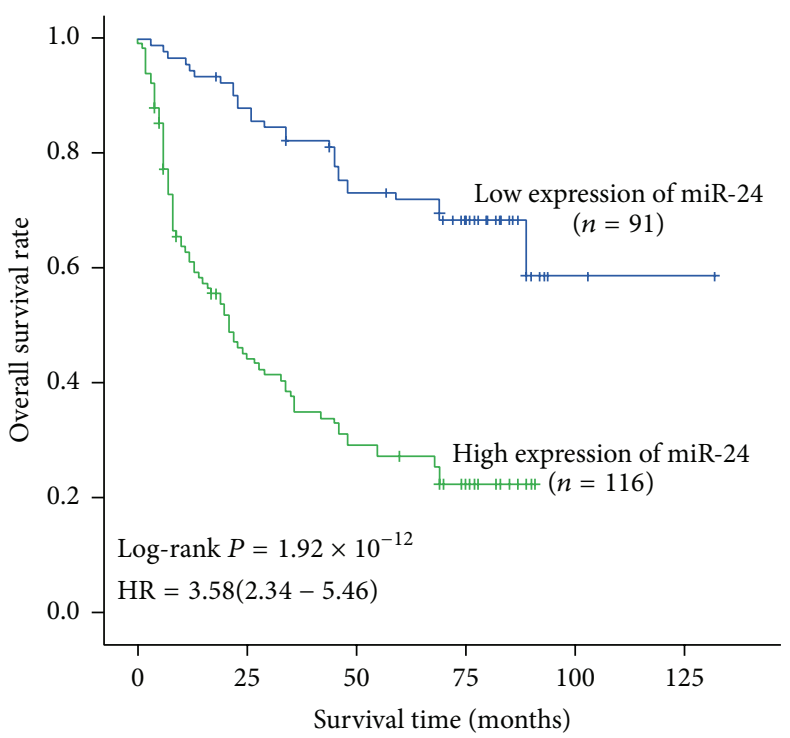

(b)

FIgURE 3: Association between survival and miR-24 expression in 207 HCC cases receiving curative treatment. According to the average expression in cancerous tissues, miR-24 expression was divided into two groups: low expression group (relative level $\leq 2$ ) and high expression group (relative level > 2). MiR-24 expression was associated with tumor reoccurrence-free survival (a) and overall survival (b) of HCC. Cumulative hazard function was plotted by Kaplan-Meier's methodology, and $P$ value was calculated with two-sided log-rank tests. Relative hazard ratio (HR) and corresponding 95\% CI of high miR-24 expression (compared with low expression) was calculated using multivariable cox regression model (including all significant variables).

3.8. MiR-24 Expression Modulated the Apoptosis of HCC Cells. We also explored the function of miR-24 in HCC cells through analyzing changes in apoptosis after the HCC cells were transfected with miR-24 mimics and its inhibitor. DNA content of transiently microRNA-transfected cells was analyzed by flow cytometry. the RAV of SMMC7721 cell lines in the miR-24 group was significantly decreased $(P<0.05)$ compared with the control group. Tumor cell apoptosis in the inhibitor group, compared with the mock group, was promoted significantly $(P<0.05)$ (Figure 6(b)). Similar 


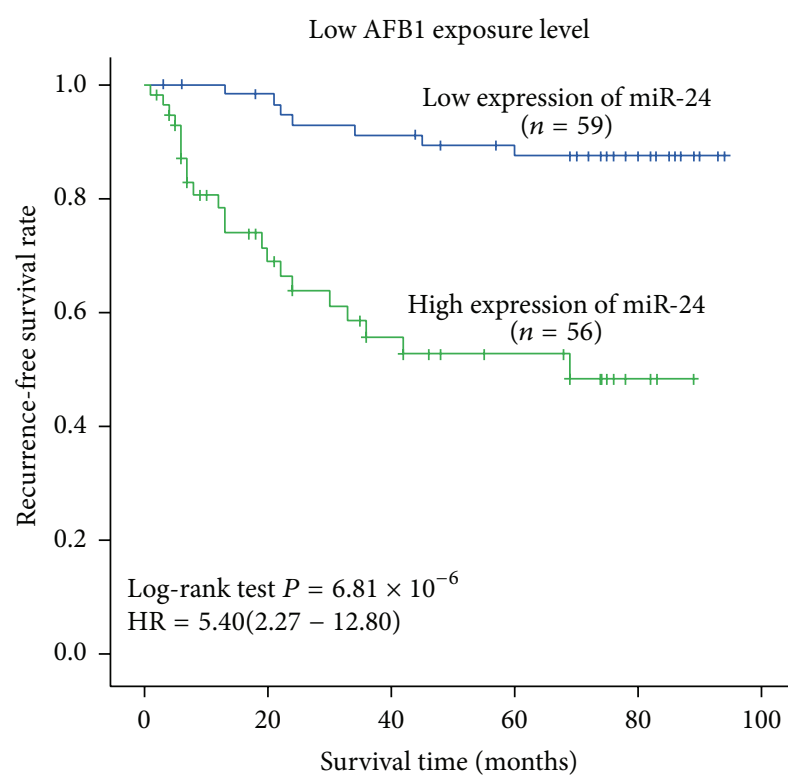

(a)

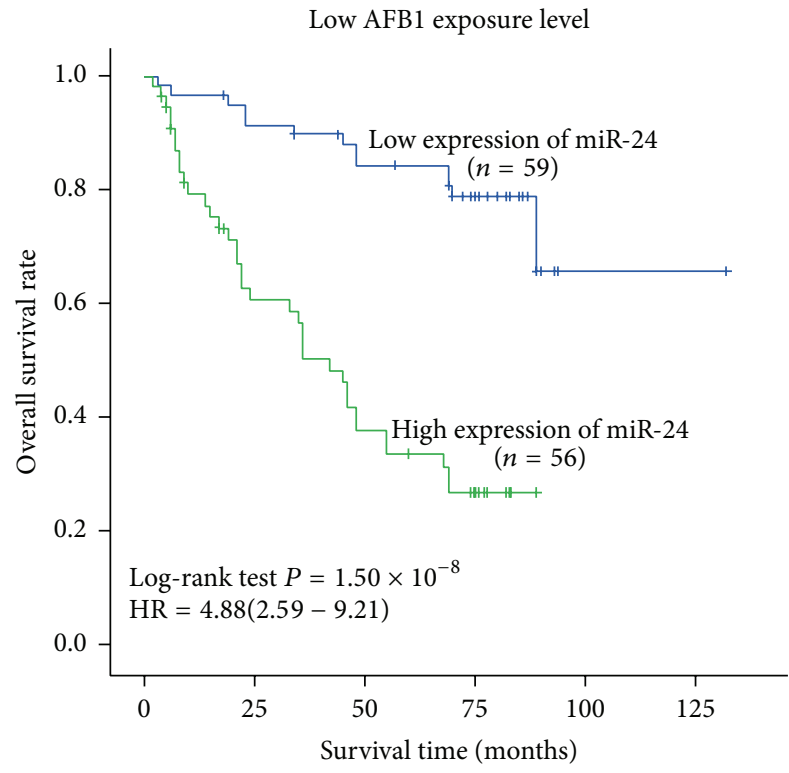

(c)

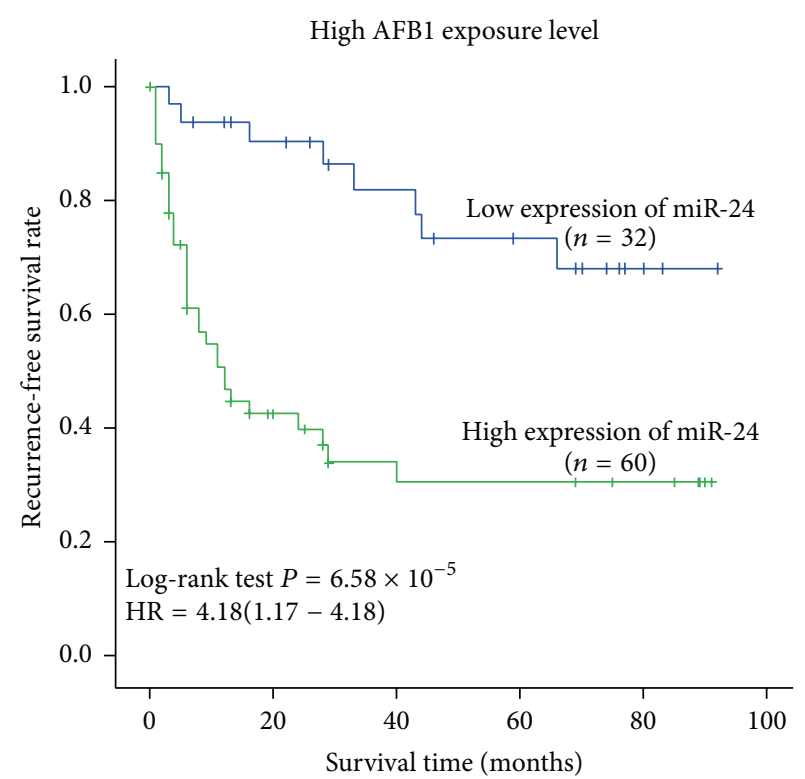

(b)

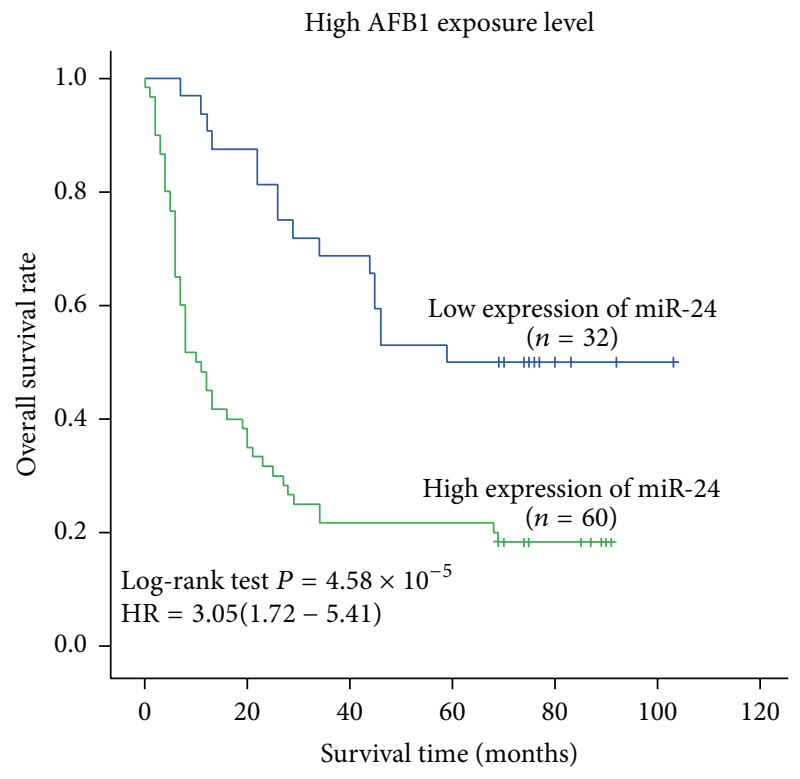

(d)

FIGURE 4: Survival analysis of miR-24 expression in strata of AFB1-DNA adduct. (a)-(b) Tumor recurrence-free survival (RFS) and miR-24 expression in strata of AFB1-DNA adduct levels. (c-d) Overall survival (OS) and miR-24 expression in strata of AFB1-DNA adduct levels. Cumulative hazard function was plotted by Kaplan-Meier's methodology, and $P$ value was calculated with two-sided log-rank tests. Relative hazard ratio (HR) and corresponding 95\% CI of high miR-24 expression (compared with low expression) was calculated using multivariable cox regression model (including all significant variables).

results were observed in the two other cells HepG2 and HCCLM3.

3.9. MiR-24 Expression Increased AFB1-DNA Adducts in the HCC Samples and SMMC-7721 Cells. To investigate the effects of miR-24 expression on AFB1-DNA formation, we analyzed the effects of miR-24 expression on AFB1-DNA formation in liver cancer tissues. Results showed that these persons having high miR-24 expression in their tumor tissues faced increasing DNA adducts levels $(3.27 \pm 1.81 \mu \mathrm{mol} / \mathrm{mol}$ DNA) compared with those with low miR-24 expression $(2.37 \pm 1.12 \mu \mathrm{mol} / \mathrm{mol}$ DNA, $P<0.01$, Figure $7(\mathrm{a}))$. A toxin experiment of AFB1 was next performed through transfecting different mimics into the SMMC7721 cells. We found that group with overexpression of miR-24 had elevated levels of AFB1-DNA adducts $(0.795 \pm 0.005 \mathrm{nmol} / \mu \mathrm{g}$ DNA) compared with control group $(0.394 \pm 0.005 \mathrm{nmol} / \mu \mathrm{g}$ DNA, $P<0.05$, Figure 6(b)). On the other hand, compared with mock group 


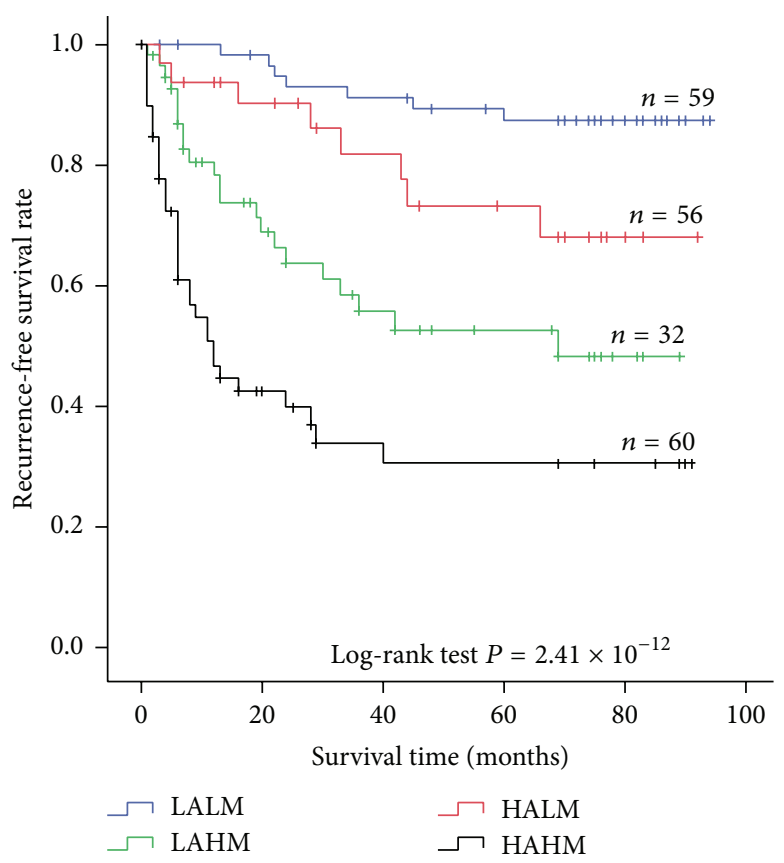

(a)

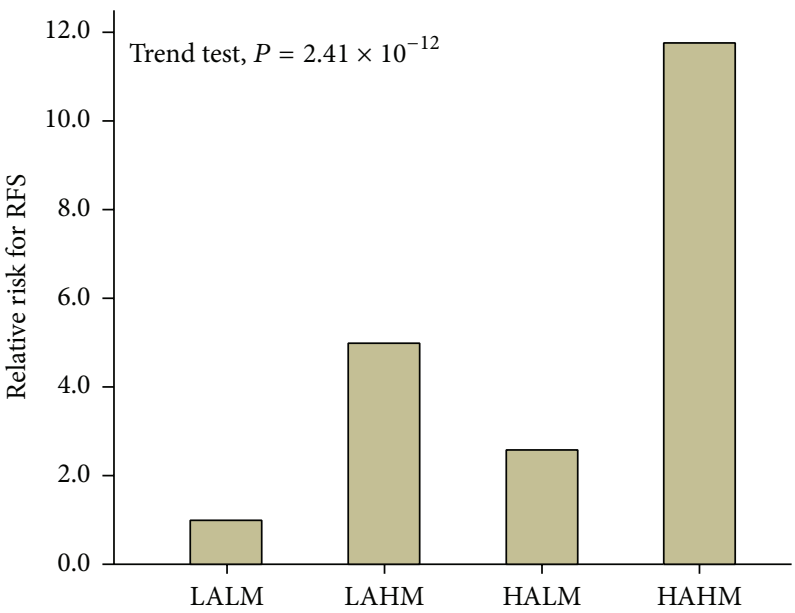

(b)

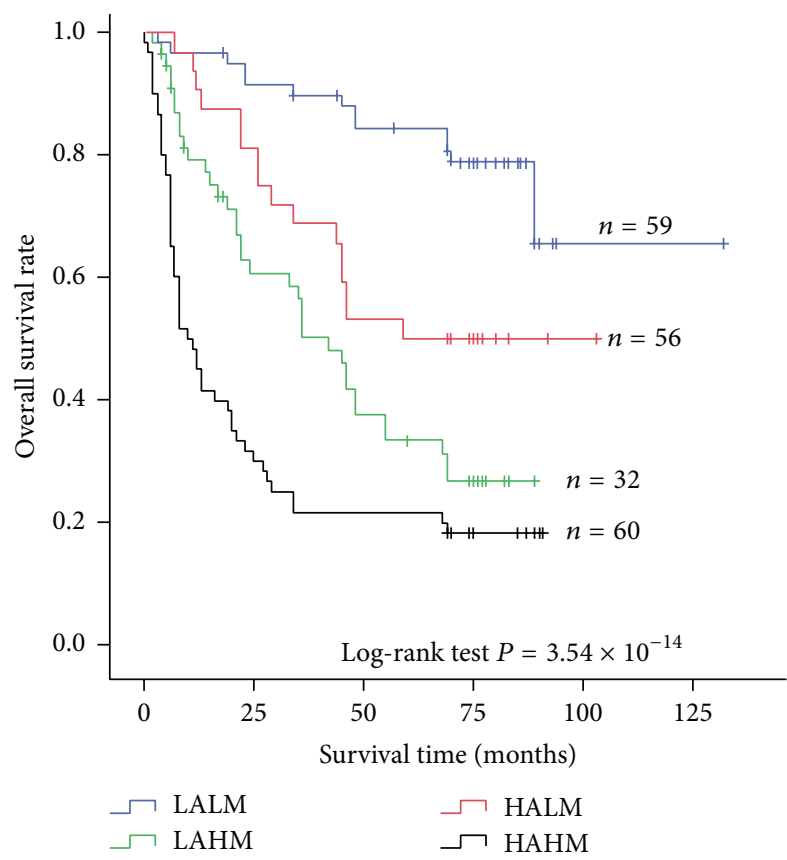

(c)

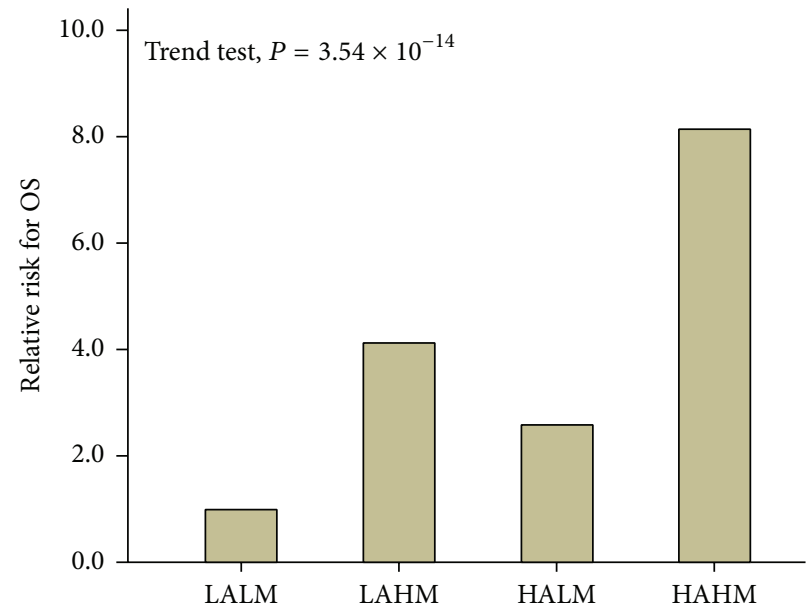

(d)

Figure 5: The joint effects of AFB1 exposure and miR-24 expression on HCC prognosis. (a and c) The joint effects of AFB1 exposure and miR-24 expression on tumor recurrence-free survival (RFS) and overall survival (OS) of HCC patients. Cumulative hazard function was plotted by Kaplan-Meier's methodology, and $P$ value was calculated with two-sided log-rank tests. (b and d) Relative hazard ratio (HR) of both AFB1 exposure and miR-24 expression on HCC. HR was calculated using multivariable cox regression model (including all significant variables). Abbreviations: LALM, the combination of low AFB1 exposure level and low miR-24 expression; LAHM, the combination of low AFB1 exposure level and high miR-24 expression; HALM, the combination of high AFB1 exposure level and low miR-24 expression; HAHM, the combination of high AFB1 exposure level and high miR-24 expression.

$(0.412 \pm 0.002 \mathrm{nmol} / \mu \mathrm{g}$ DNA $)$, cells transfected by miR-24 inhibitor featured decreased levels of DNA adducts $(0.181 \pm$ $0.002 \mathrm{nmol} / \mu \mathrm{g}$ DNA, $P<0.05$, Figure 7(b)).

\section{Discussion}

In Guangxi Zhuang Autonomous Region, China, HCC is the most common cancer type, with an incidence rate of
$53 / 100,000$ per year and a death rate of 37-55/100,000 annually [1, 2]. Clinical-epidemiologic evidence suggests AFB1 exposure is a major risk factor for liver cancer in Guangxi Region [1]. AFB1 is an important I-type chemical carcinogen produced by some strains of the moulds aspergillus parasiticus and aspergillus flavus that grow readily on such foodstuffs as corn and groundnuts stored in damp conditions. Once ingested, this toxin is metabolized mainly by cytochrome 
TABLE 3: Expression levels of miR-24 and clinicopathological features of cases.

\begin{tabular}{|c|c|c|c|c|c|c|}
\hline & \multicolumn{2}{|c|}{ Low expression } & \multicolumn{2}{|c|}{ High expression } & \multirow{2}{*}{ OR $(95 \% \mathrm{CI})^{\mathrm{a}}$} & \multirow{2}{*}{$P$} \\
\hline & $n$ & $\%$ & $n$ & $\%$ & & \\
\hline AFB1 exposure & & & & & & $3.10 \times 10^{-2}$ \\
\hline Low level & 59 & 64.8 & 56 & 48.3 & Reference & \\
\hline High level & 32 & 35.2 & 60 & 51.7 & $1.92(1.06-3.46)$ & \\
\hline Tumor size & & & & & & $1.91 \times 10^{-2}$ \\
\hline$\leq 5 \mathrm{~cm}$ & 53 & 58.2 & 48 & 41.4 & Reference & \\
\hline$>5 \mathrm{~cm}$ & 38 & 41.8 & 68 & 58.6 & $2.01(1.12-3.60)$ & \\
\hline Tumor grade & & & & & & $3.92 \times 10^{-2}$ \\
\hline I-II & 72 & 79.1 & 78 & 67.3 & Reference & \\
\hline III-IV & 19 & 20.9 & 38 & 32.7 & $2.10(1.04-4.27)$ & \\
\hline MVD & & & & & & $1.93 \times 10^{-2}$ \\
\hline Low & 50 & 54.9 & 38 & 32.8 & Reference & \\
\hline High & 41 & 45.1 & 78 & 67.2 & $2.62(1.43-4.81)$ & \\
\hline
\end{tabular}

adjusted by age, sex, race, HBV and HCV infection status, and smoking and drinking status.

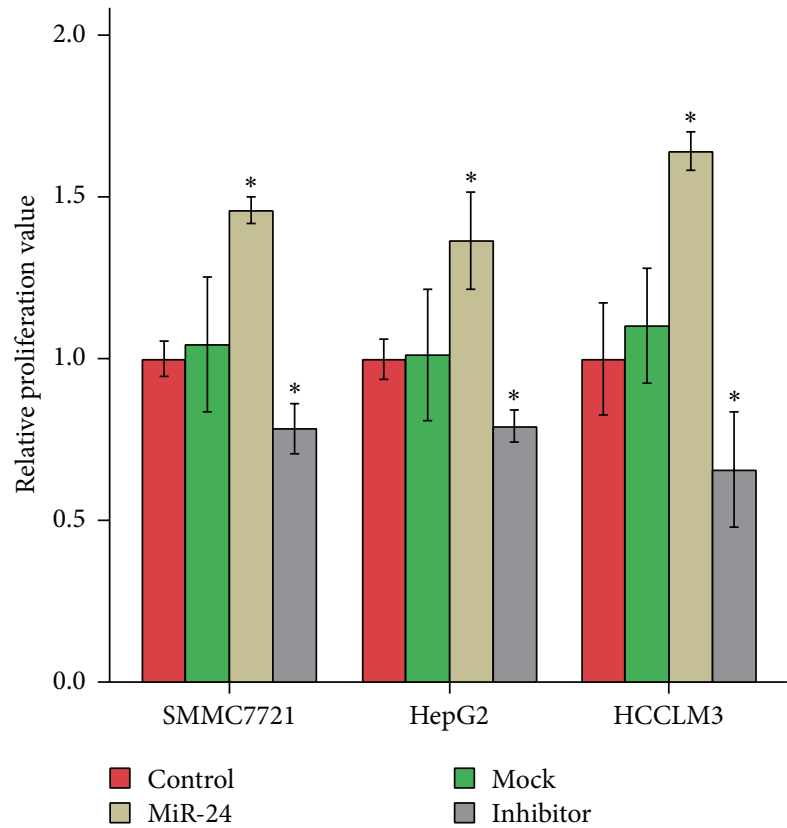

(a)

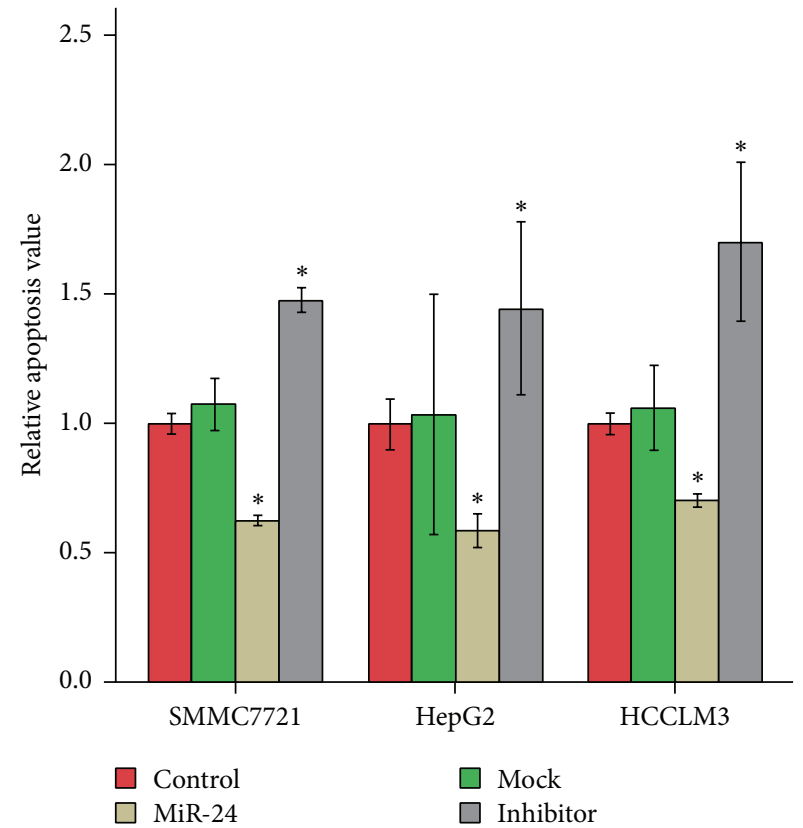

(b)

FIGURE 6: MiR-24 expression modified the proliferation and the apoptosis of HCC cancer cells. According to the types of mimics transfected, cell lines were divided into four groups: control group (control, by null mimics), mock group (mock, by mock mimics); miR-24 group (miR-24, by mature miR-24 mimics), and inhibitor group (inhibitor, by inhibitor of mature miR-24). (a) Association between miR-24 expression and cancer cell proliferation was elucidated using the CCK-8 assays. Relative proliferation value was calculated using control group as a reference. (b) Relationship between miR-24 expression and cancer cell apoptosis was evaluated by flow cytometry technique. Relative apoptosis value was calculated using control group as a reference. Data were analyzed using one-way ANOVA with Bonferroni corrections. Asterisk, $P<0.05$.

P450 into the genotoxic metabolic aflatoxin B1-exo-8,9epoxide (AFBO). AFBO is able to bind to DNA and causes genomic DNA damage and induces HCC $[1,2,20]$. In our study, about $2.9 \mu \mathrm{mol} / \mathrm{mol}$ DNA of AFB1 adducts was tested in the liver cancer tissue samples, and AFB1-exposure status was also found to be associated with the poorer outcome of HCC. These results suggest that AFB1 is an important marker for HCC prognosis. However, because of metastasis or other causes, most AFB1-related HCC cases are already in an incurable stage with an extremely poor prognosis at the time of diagnosis [21]. Therefore, new prognosis biomarkers and therapies have been expected, but no remarkable advances have been made in the treatment and prognostic prediction of this malignant tumor.

Increasing evidence has shown that microRNAs may be a type of significant prognosis factor and potential therapeutic 


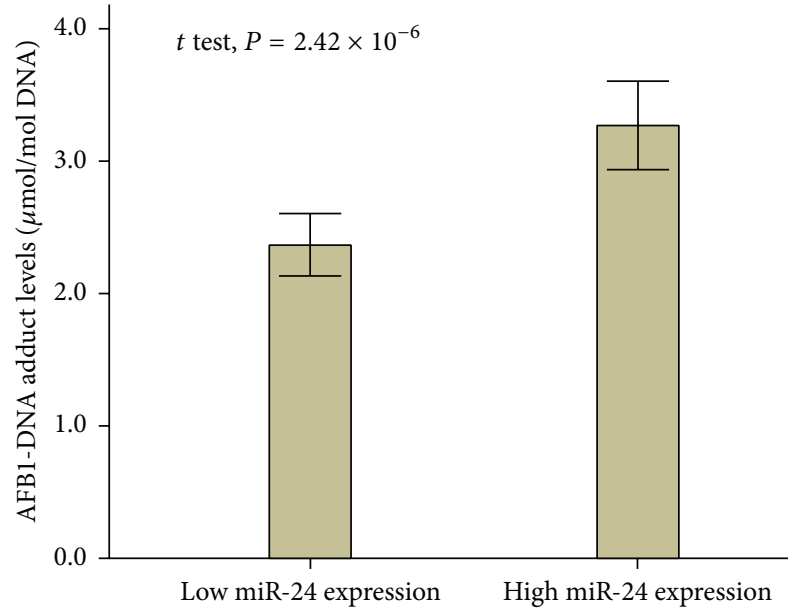

(a)

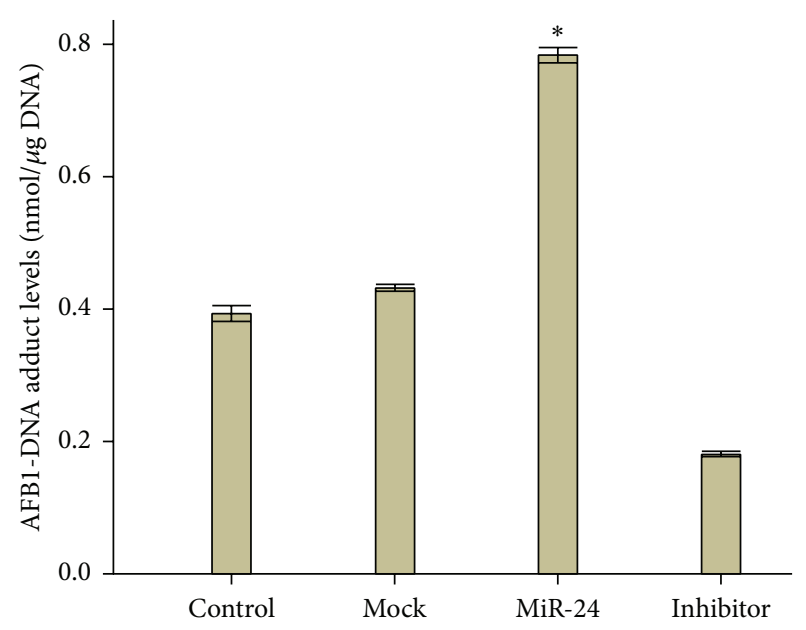

(b)

FIGURE 7: AFB1-DNA adducts formation in AFB1-treated SMMC7721 cells with overexpression of miR-24 (see Section 2). Levels of AFB1DNA adducts were tested using comparative ELISA. Data were analyzed from three independent tests using one-way ANOVA with Bonferroni corrections. Asterisk, $P<0.05$.

target for some malignant tumors including HCC $[16,22,23]$. MicroRNAs, a class of small noncoding single-stranded RNA with about 20 nucleotide sequence, are formed from the sequential processing of primary transcripts by two RNase enzymes, Drosha and Dicer $[6,24]$. Through regulating gene expression, they functionally involve in cell differentiation, cell proliferation, cell apoptosis, physiological timing, metabolism, and hormone secretion [25, 26]. Moreover, increasing reports have exhibited that microRNAs may play a role in the aetiology and pathogenesis of various cancers by targeting a number of oncogenes or tumour suppressor genes [7]. The dysregulation of microRNA expression may correlate with the prognosis of some tumors such as HCC $[16,23]$.

Of particular recent interest is the possible contribution of miR-24 to tumor prognosis and tumorigenesis [23, 27, 28]. MiR-24, an important abundant microRNA encoded by the corresponding gene that maps to human chromosome 9q22 and 19p13 regions, is well conserved between various species and is expressed in normal tissues such as adipose tissue, mammary gland, kidney, and differentiated skeletal muscles [29]. Increasing evidence has shown that the miR-24 is frequently altered in liver cancer [11-13, 22, 23]. The dysregulation of miR-24 expression may modify tumor prognosis $[22,23]$. In the present study, we collected 207 HCC tissue samples from Guangxi Zhuang Autonomous Region, both a high AFB1 exposure area and a high epidemic area of HCC in China, and investigated the possible effects of miR-24 expression on HCC prognosis. We found that HCC patients having high miR-24 expression in the tumor tissues had a significant poor RFS and OS compared with those with low expression of miR-24. Multivariate Cox regression analysis showed high miR-24 expression increased 3.75-times tumor reoccurrence risk and 2.58-times death risk; moreover, this risk did not depend on the clinic-pathological change. Supporting our results, a recent study has shown the dysregulation of miR24 expression can modify the prognosis of cirrhotic HCC
[22]. These data implied that miR-24 expression might be an independent prognostic factor for HCC and that its abnormal expression could be used as a prognostic marker for HCC.

In this study, we stratified HCC patients with respect to AFB1-DNA adducts levels and investigated the effects of miR24 expression on HCC prognosis in different AFB1 exposure status. This was done primarily because the cause of HCC might modify the levels of miR-24 expression. Poorer outcome was found in these patients having high AFB1 exposure, suggesting possible interactive effects between environment exposure and gene expression on HCC prognosis. Next joint analysis proved this positive interaction. Therefore, it is well known that postoperative adjuvant therapy might significantly improve the prognosis of HCC cases, especially with high AFB1 exposure status.

Recent reports have exhibited that miR-24 may be involved in different cancers and play important role in carcinogenesis, such as gastric cancer [30], colorectal cancer [31], cervical cancer [32], oral squamous cell carcinoma [33], breast cancer [9], leukemia [34, 35], glioma [36], and lung cancer [10]. Several target genes of miR-24 have been discovered, including PKC-alpha, MXI 1, DHFR, ALK4, FAF1, DND1, AE1, p14ARF, and XIAP $[9,10,27,28,30-$ 42]. In this study, we also explored the association between miR-24 expression and HCC tumorigenesis through testing the expression difference of miR-24 in the different tissues (including tumor tissues and paired noncancerous matched tissues). Higher expression of miR-24 was observed in the tumor tissues, and this increasing expression of miR-24 was correlated with larger tumor size, tumor dedifferentiation, and increasing MVD. Our results also exhibited that the overexpression of miR-24 progressed cell proliferation and inhibited cell apoptosis. On the contrary, the suppression of miR-24 expression hindered cell proliferation and promoted cell apoptosis. Furthermore, different expression levels of 
miR-24 were found in the different degrees of differentiation; and HCC cells with poor differentiation and high infiltrating capacity had an increasing expression of miR-24. In accordance with our results, several recent studies have demonstrated that upregulation of miR-24 is involved in the tumorigenesis of HCC $[11-13,23,43,44]$. Taken together, these results suggested that the dysregulation of miR-24 expression might play an important role in the tumorigenesis of HCC through promoting tumor angiogenesis, proliferation, tumor invasion, and metastasis [11-13].

Interestingly, we found that high expression of miR-24 could promote AFB1-DNA formation and increase adducts mount. This is possibly because miR-24 can target some detoxification enzyme genes [45] and reduce their detoxification capacity and subsequently result in the accumulation of AFB1-DNA adducts. Additionally, our previous reports showed that low expression of DNA repair by microRNA would decrease the DNA repair capacity and subsequently increase DNA damage amount and HCC risk [14-16]. These results provided new insights into the mechanism of HCC induced by AFB1.

The present study had several limitations. Only 207 HCC patients were enrolled in the analysis of the clinicpathological characteristics and prognosis. We would like to confirm the findings in a larger HCC patient population. Another important limitation was that we did not do migration and invasiveness assays to validate the involvement of miR-24 in tumour migration and invasion. Although the status of miR-24 expression was investigated in cases of HCC, other microRNAs, such as microRNA-629 and microRNA124, which may be involved in HCC tumorigenesis and modify HCC prognosis [11], were not evaluated. Additionally, because the liver disease itself may affect the metabolism of AFB1 and modify the levels of AFB1 DNA adducts, the increased death risk and tumor reoccurring risk with AFB1 exposure status noted in this study was probably underestimated. Therefore, more microRNAs deserve further elucidation based on a large sample and the combination of genes and AFB1 exposure.

\section{Conclusions}

In summary, this study is, to the best of our knowledge, the first report that describes miR-24 expression in AFB1related liver cancer and its associations with HCC prognosis. Our results showed that miR-24, as an oncogene, was overexpressed in liver cancer tissues and could be considered as a potential prognostic factor for HCC. Furthermore, overexpression of this microRNA was associated with AFB1related HCC tumorigenesis. Therefore, more detailed molecular pathogenesis analysis deserves elucidation based on the results from large samples. Expanding insights into the key role of dysregulated microRNAs involved in liver tumorigenesis will yield important clues for the complicated molecular pathogenesis of HCC and may assist in the development of new therapeutic regimens for HCC patients, especially from high AFB1 exposure areas.

\section{Conflict of Interests}

The authors declare no competing financial interests.

\section{Authors' Contribution}

Yi-Xiao Liu, Xi-Dai Long, and Zhi-Feng Xi contributed equally to this work.

\section{Acknowledgments}

The authors thank Dr. Qiu-Xiang Liang, Dr. Yun Yi, and Dr. Yuan-Feng Zhou for sample collection and management and Dr. Hua Huang for molecular biochemical technique. They also thank all members of Department of Medical Test and Infective Control, Affiliated Hospital of Youjiang Medical College for Nationalities for their help. This study was supported in part by the National Natural Science Foundation of China (nos. 81160255 and 81372639), the Innovation Program of Guangxi Municipal Education Department (no. 201204LX674), Innovation Program of Shanghai Municipal Education Commission (no. 13YZ035), the Natural Science Foundation of Guangxi (no. 2013GXNSFAA019251), and "Shu Guang” Project (supported by Shanghai Municipal Education Commission and Shanghai Education Development Foundation, no. 13SG19).

\section{References}

[1] Q. Xia, X. Y. Huang, F. Xue et al., "Genetic polymorphisms of DNA repair genes and DNA repair capacity related to aflatoxin b1 (AFB1)-induced DNA damages," in New Research Directions in DNA Repair, C. Chen, Ed., pp. 377-412, InTech, Rijeka, Croatia, 1 edition, 2013.

[2] X. D. Long, J. G. Yao, Z. Zeng et al., "DNA repair capacityrelated to genetic polymorphisms of DNA repair genes and aflatoxin B1-related hepatocellular carcinoma among Chinese population," in DNA Repair, (Amst), I. Kruman, Ed., pp. 505524, InTech, Rijeka, Croatia, 2011.

[3] A. Jemal, F. Bray, M. M. Center, J. Ferlay, E. Ward, and D. Forman, "Global cancer statistics," CA Cancer Journal for Clinicians, vol. 61, no. 2, pp. 69-90, 2011.

[4] J. Vera, X. Lai, U. Schmitz, and O. Wolkenhauer, "MicroRNAregulated networks: the perfect storm for classical molecular biology, the ideal scenario for systems biology," Advances in Experimental Medicine and Biology, vol. 774, pp. 55-76, 2013.

[5] B. D. Aguda, "Modeling microRNA-transcription factor networks in cancer," Advances in Experimental Medicine and Biology, vol. 774, pp. 149-167, 2013.

[6] N. Lynam-Lennon, S. G. Maher, and J. V. Reynolds, "The roles of microRNA in cancer and apoptosis," Biological Reviews, vol. 84, no. 1, pp. 55-71, 2009.

[7] B. Zhang, X. Pan, G. P. Cobb, and T. A. Anderson, "microRNAs as oncogenes and tumor suppressors," Developmental Biology, vol. 302, no. 1, pp. 1-12, 2007.

[8] S. Griffiths-Jones, "The microRNA registry," Nucleic Acids Research, vol. 32, pp. D109-D111, 2004.

[9] E. C. Martin, S. Elliott, L. V. Rhodes et al., "Preferential star strand biogenesis of pre-miR-24-2 targets PKC-alpha and 
suppresses cell survival in MCF-7 breast cancer cells," Molecular Carcinogenesis, vol. 53, no. 1, pp. 38-48, 2014.

[10] T. Franchina, V. Amodeo, G. Bronte et al., "Circulating miR22, miR-24 and miR-34a as novel predictive biomarkers to pemetrexed-based chemotherapy in advanced non-small cell lung cancer," Journal of Cellular Physiology, vol. 229, no. 1, pp. 97-99, 2014.

[11] M. Hatziapostolou, C. Polytarchou, E. Aggelidou et al., "An HNF $4 \alpha$-miRNA inflammatory feedback circuit regulates hepatocellular oncogenesis," Cell, vol. 147, no. 6, pp. 1233-1247, 2011.

[12] C. E. Rogler, L. LeVoci, T. Ader et al., "MicroRNA-23b cluster microRNAs regulate transforming growth factor-beta/bone morphogenetic protein signaling and liver stem cell differentiation by targeting Smads," Hepatology, vol. 50, no. 2, pp. 575-584, 2009.

[13] X. Z. Meng, T. S. Zheng, X. Chen et al., "microRNA expression alteration after arsenic trioxide treatment in HepG-2 cells," Journal of Gastroenterology and Hepatology, vol. 26, no. 1, pp. 186-193, 2011.

[14] X. D. Long, D. Zhao, C. Wang et al., "Genetic polymorphisms in DNA repair genes XRCC4 and XRCC5 and aflatoxin B1-related hepatocellular carcinoma," Epidemiology, vol. 24, no. 5, pp. 671681, 2013.

[15] X. D. Long, J. G. Yao, Z. Zeng et al., "Polymorphisms in the coding region of $\mathrm{X}$-ray repair complementing group 4 and aflatoxin B1-related hepatocellular carcinoma," Hepatology, vol. 58, no. 1, pp. 171-181, 2013.

[16] X. Y. Huang, J. G. Yao, H. D. Huang et al., "MicroRNA-429 modulates hepatocellular carcinoma prognosis and tumorigenesis," Gastroenterology Research and Practice, vol. 2013, Article ID 804128, 10 pages, 2013.

[17] D. J. Dabbs, K. R. Geisinger, F. Ruggiero, S. S. Raab, M. Nalesnik, and J. F. Silverman, "Recommendations for the reporting of tissues removed as part of the surgical treatment of malignant liver tumors," Human Pathology, vol. 35, no. 11, pp. 1315-1323, 2004.

[18] X. D. Long, Y. Ma, Y. F. Zhou, A. Ma, and G. Fu, "Polymorphism in xeroderma pigmentosum complementation group $\mathrm{C}$ codon 939 and aflatoxin B1-related hepatocellular carcinoma in the Guangxi population," Hepatology, vol. 52, no. 4, pp. 1301-1309, 2010.

[19] X. D. Long, Y. Ma, Y. F. Zhou et al., "XPD codon 312 and 751 polymorphisms, and AFB1 exposure, and hepatocellular carcinoma risk," BMC Cancer, vol. 9, no. 1, p. 400, 2009.

[20] T. W. Kensler, B. D. Roebuck, G. N. Wogan, and J. D. Groopman, "Aflatoxin: a 50-year Odyssey of mechanistic and translational toxicology," Toxicological Sciences, vol. 120, supplement 1, pp. S28-S48, 2011.

[21] Y. F. Sun, Y. Xu, X. R. Yang et al., "Circulating stem cell-like epithelial cell adhesion molecule-positive tumor cells indicate poor prognosis of hepatocellular carcinoma after curative resection," Hepatology, vol. 57, no. 4, pp. 1458-1468, 2013.

[22] A. Salvi, E. Abeni, N. Portolani, S. Barlati, and G. De Petro, "Human hepatocellular carcinoma cell-specific miRNAs reveal the differential expression of miR-24 and miR-27a in cirrhotic/non-cirrhotic HCC," International Journal of Oncology, vol. 42, no. 2, pp. 391-402, 2013.

[23] Z. B. Han, L. Zhong, M. J. Teng et al., "Identification of recurrence-related microRNAs in hepatocellular carcinoma following liver transplantation," Molecular Oncology, vol. 6, no. 4, pp. 445-457, 2012.
[24] S. K. Shenouda and S. K. Alahari, "MicroRNA function in cancer: oncogene or a tumor suppressor?" Cancer and Metastasis Reviews, vol. 28, no. 3-4, pp. 369-378, 2009.

[25] D. P. Bartel, "MicroRNAs: genomics, biogenesis, mechanism, and function," Cell, vol. 116, no. 2, pp. 281-297, 2004.

[26] V. Ambros, “The functions of animal microRNAs," Nature, vol. 431, no. 7006, pp. 350-355, 2004.

[27] Y. Xie, L. A. Tobin, J. Camps et al., "MicroRNA-24 regulates XIAP to reduce the apoptosis threshold in cancer cells," Oncogene, vol. 32, no. 19, pp. 2442-2451, 2013.

[28] N. Srivastava, S. Manvati, A. Srivastava et al., "MiR-24-2 controls H2AFX expression regardless of gene copy number alteration and induces apoptosis by targeting antiapoptotic gene BCL-2: a potential for therapeutic intervention," Breast Cancer Research, vol. 13, no. 2, p. R39, 2011.

[29] J. H. Gibcus, L. P. Tan, G. Harms et al., "Hodgkin lymphoma cell lines are characterized by a specific miRNA expression profile," Neoplasia, vol. 11, no. 2, pp. 167-176, 2009.

[30] Y. Tsukamoto, C. Nakada, T. Noguchi et al., "MicroRNA-375 is downregulated in gastric carcinomas and regulates cell survival

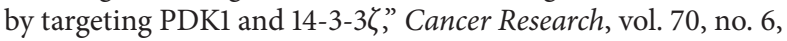
pp. 2339-2349, 2010.

[31] P. J. Mishra, B. Song, P. J. Mishra et al., "Mir-24 tumor suppressor activity is regulated independent of p53 and through a target site polymorphism," PLoS ONE, vol. 4, no. 12, Article ID e8445, 2009.

[32] X. Wang, S. Tang, S. Le et al., "Aberrant expression of oncogenic and tumor-suppressive microRNAs in cervical cancer is required for cancer cell growth," PLoS ONE, vol. 3, no. 7, Article ID e2557, 2008.

[33] S. C. Lin, C. J. Liu, J. A. Lin, W. F. Chiang, P. Hung, and K. Chang, "miR-24 up-regulation in oral carcinoma: positive association from clinical and in vitro analysis," Oral Oncology, vol. 46, no. 3, pp. 204-208, 2010.

[34] T. Nguyen, A. Rich, and R. Dahl, "MiR-24 promotes the survival of hematopoietic cells," PLoS ONE, vol. 8, no. 1, Article ID e55406, 2013.

[35] Q. Wang, Z. Huang, H. Xue et al., "MicroRNA miR-24 inhibits erythropoiesis by targeting activin type I receptor ALK4," Blood, vol. 111, no. 2, pp. 588-595, 2008.

[36] W. Xu, M. Liu, X. Peng et al., "miR-24-3p and miR-27a$3 p$ promote cell proliferation in glioma cells via cooperative regulation of MXI1," International Journal of Oncology, vol. 42, no. 2, pp. 757-766, 2013.

[37] A. Talasila, H. Yu, M. Ackers-Johnson et al., "Myocardin regulates vascular response to injury through miR-24/-29a and platelet-derived growth factor receptor-beta," Arteriosclerosis, Thrombosis, and Vascular Biology, vol. 33, no. 10, pp. 2355-2365, 2013.

[38] L. Chen, A. Zhang, Y. Li et al., "MiR-24 regulates the proliferation and invasion of glioma by ST7L via beta-catenin/Tcf-4 signaling," Cancer Letters, vol. 329, no. 2, pp. 174-180, 2013.

[39] S. Giglio, R. Cirombella, R. Amodeo, L. Portaro, L. Lavra, and A. Vecchione, "MicroRNA miR-24 promotes cell proliferation by targeting the CDKs inhibitors p27Kip1 and p16INK4a," Journal of Cellular Physiology, vol. 228, no. 10, pp. 2015-2023, 2013.

[40] W. W. Du, L. Fang, M. Li et al., "MicroRNA miR-24 enhances tumor invasion and metastasis by targeting PTPN9 and PTPRF to promote EGF signaling," Journal of Cell Science, vol. 126, part 6, pp. 1440-1453, 2013. 
[41] W. Qin, Y. Shi, B. Zhao et al., "miR-24 regulates apoptosis by targeting the Open Reading Frame (ORF) region of FAF1 in cancer cells," PLoS ONE, vol. 5, no. 2, Article ID e9429, 2010.

[42] K. H. To, S. Pajovic, B. L. Gallie, and B. L. Thériault, "Regulation of p14ARF expression by miR-24: a potential mechanism compromising the p53 response during retinoblastoma development," BMC Cancer, vol. 12, p. 69, 2012.

[43] A. Gougelet and S. Colnot, "MicroRNA-feedback loop as a key modulator of liver tumorigenesis and inflammation," World Journal of Gastroenterology, vol. 19, no. 4, pp. 440-444, 2013.

[44] X. Liu, T. Wang, T. Wakita, and W. Yang, "Systematic identification of microRNA and messenger RNA profiles in hepatitis $\mathrm{C}$ virus-infected human hepatoma cells," Virology, vol. 398, no. 1, pp. 57-67, 2010.

[45] Y. Oda, M. Nakajima, T. Mohri et al., "Aryl hydrocarbon receptor nuclear translocator in human liver is regulated by miR-24," Toxicology and Applied Pharmacology, vol. 260, no. 3, pp. 222-231, 2012. 


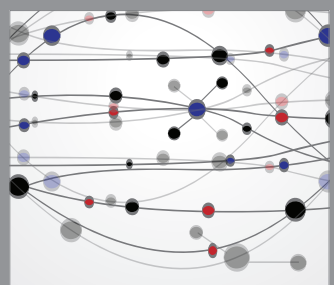

The Scientific World Journal
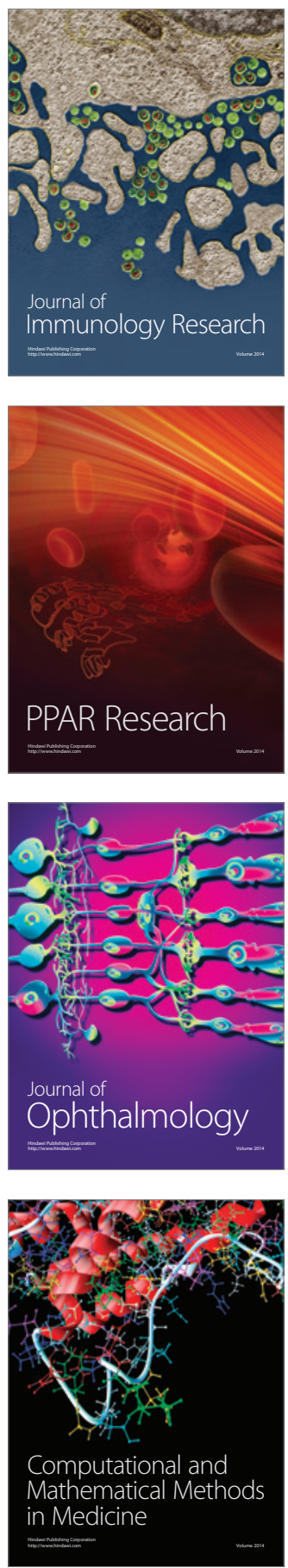

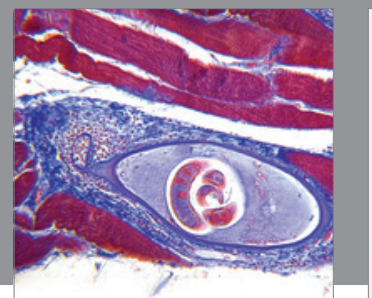

Gastroenterology

Research and Practice
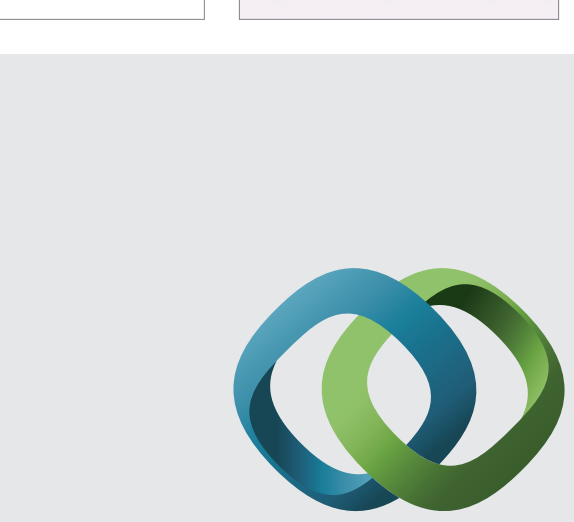

\section{Hindawi}

Submit your manuscripts at

http://www.hindawi.com
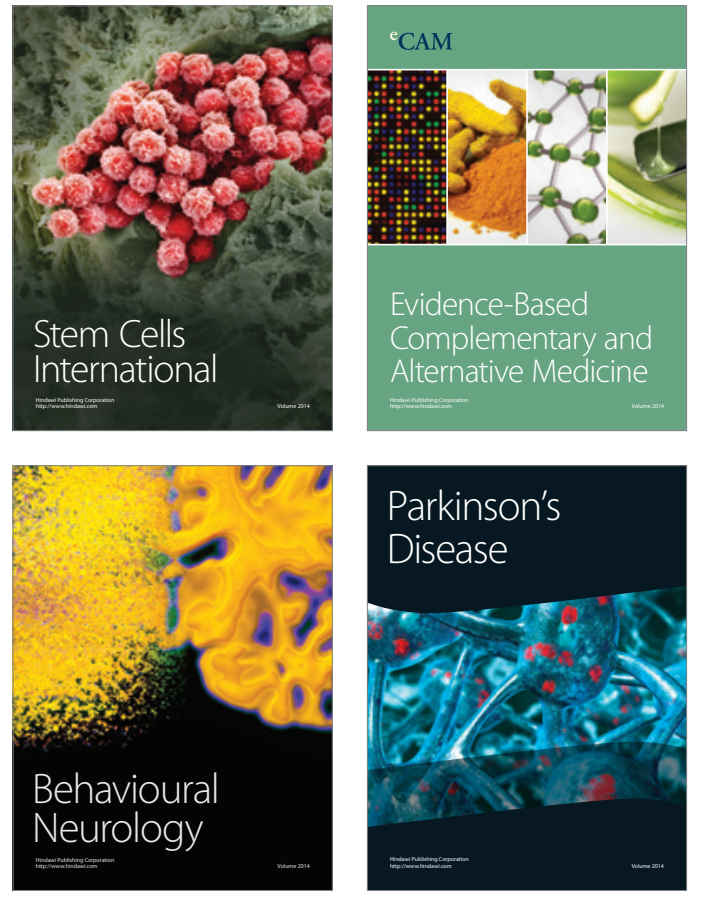
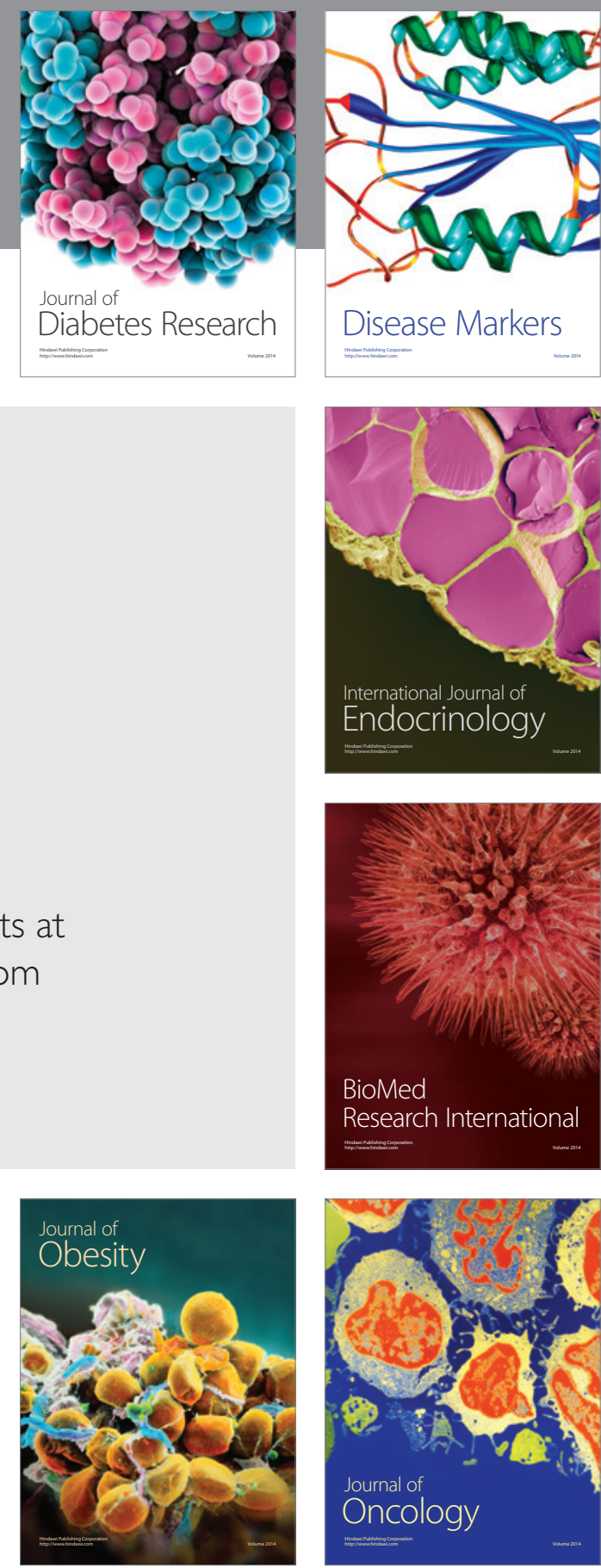

Disease Markers
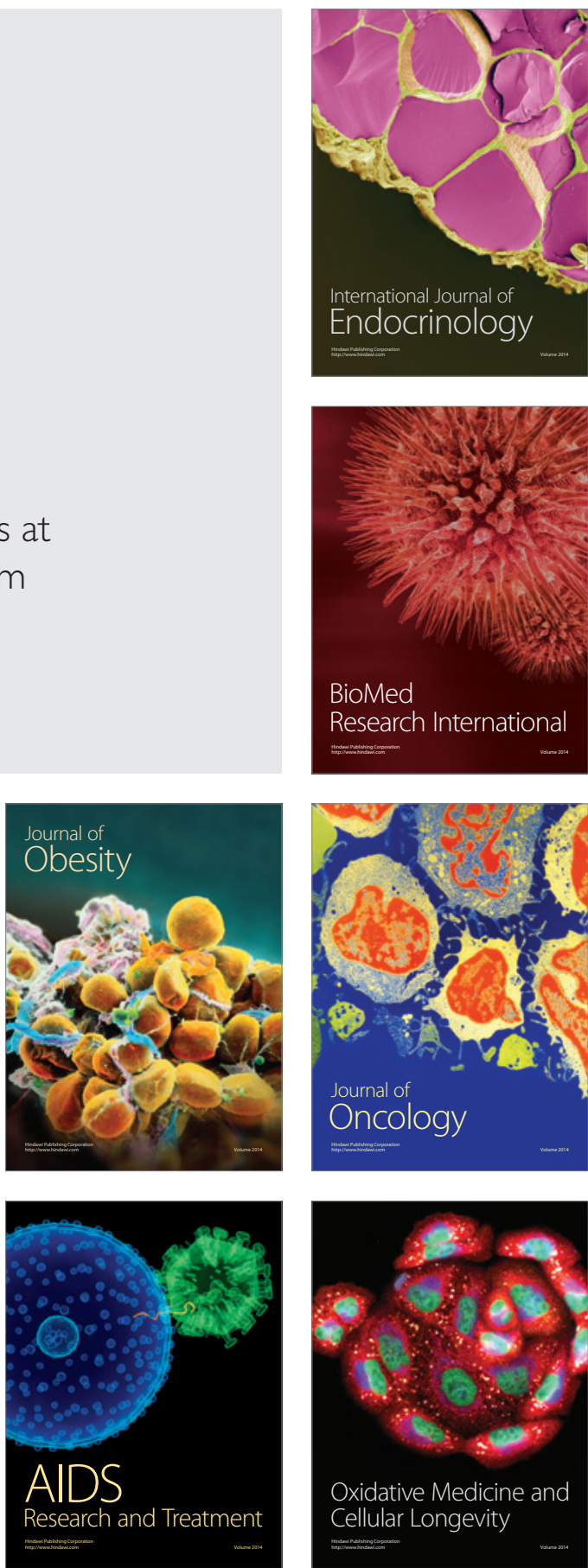